\title{
Effect of Betulinic acid Extraction from Guava (Psidium guajava Linn.) Leaves Against Human Cholangiocarcinoma Cells
}

\author{
Rassameepen Phonarknguen', Saksit Nobsathian², Kanjana Assawasuparerk ${ }^{3 *}$
}

\begin{abstract}
Background: Betulinic acid (BA), a pentacyclic triterpene glycoside extract from guava (Psidium guajava Linn.) leaves, displays a variety of biological activities which exhibit cancer therapeutic properties associated with cancer growth inhibition in various kinds of human cancer cells including brain, breast, colorectal, cervical, lung and prostate gland. However, the effects on human cholangiocarcinoma cells have not previously been reported. Current study, we evaluated the activity of BA against human cholangiocarcinoma (HuCCA) cells. Methods: The cytotoxicity analysis was measured by using MTT assay on HuCCA and BHK-21 cells. Analysis of apoptosis was evaluated by using staining with Hoechst 33342 and quantitative real-time PCR. Results: The BA $(50-800 \mu \mathrm{g} / \mathrm{mL})$ significantly reduced the viability of HuCCA cells in a dose-dependent action with $50 \%$ inhibitory concentration ( $\mathrm{IC}_{50}$ ) of $92.45 \mu \mathrm{g} / \mathrm{mL}$ at 24 $\mathrm{h}$. It also induced apoptosis signaling pathway, such as nuclear chromatin condensation and fragmentation. Quantitative real-time PCR analysis demonstrated that BA increased p53, Bax and caspase-3 expression whilst it decreased Bcl-2 expression in the HuCCA cells in a dose dependent manner. Conclusion: BA can inhibit the HuCCA cell viability and induce apoptosis of neoplastic cells. This study indicates that BA has effective treatment for cholangiocarcinoma in vitro. Consequently, BA may be used as a novel therapeutic agent for the treatment of cholangiocarcinoma in the future.
\end{abstract}

Keywords: Betulinic acid- guava leaves (Psidium guajava Linn.)- apoptosis- cholangiocarcinoma cell

Asian Pac J Cancer Prev, 23 (2), 583-590

\section{Introduction}

Cholangiocarcinoma (CCA) is a deadly cancer of the biliary epithelium, that arise from mutation of the epithelial cells lining the biliary ducts (Fava and Lorenzini, 2011; Gatto et al., 2010). It is an important health problem worldwide, especially in many Asian countries (Gores, 2003; Sripa and Pairojkul, 2008; Shin et al., 2010; Sripa et al., 2011). In the Thailand's northeastern region there is the highest incident rate of cholangiocarcinoma in this area, where the local population consume raw freshwater fish or uncooked fish contaminated with metacercarial cysts of liver fluke (Opisthorchis viverrini). The liver fluke has been reported for its associated with cholangiocarcinoma (Haswell-Elkins et al., 1994). Among the remedies for CCA, the chemotherapy using 5-fluorouracil (5-FU) is relatively incompetent for the treatment (Hejna et al., 1998). The cancer combination treatments for CCA using chemotherapy and radiotherapy might cause serious side effects (sirica, 2005). Accordingly, for this and other types of irremediable cancer, alternative cancer treatments without side effects have been extensively sought after. Various extracts of natural products and herbal plants have been found to be a medically useful source for cancer (Battle et al., 2005). The medicinal plants display their biological and pharmacological activities against cancers and have been used as therapeutic agents (Gertsch et al., 2003; Koehn and Carter, 2005; Mann, 2002). Various plants derived from natural products may promote are capable of using as anticancer drugs, among which are plant triterpenoids compound (Rita et al., 2009).

Psidium guajava Linn. Guava belongs to the order of Myrtales, a family of Myrtaceae. Guava has been well known as an essential plant as well as a native medicinal plant in tropical and subtropical countries, including in Taiwan, Hawaii, Thailand, Philippines and Malaysia (Chen et al., 2007; Anand et al., 2016). Several parts of the plant has been used extensively in the indigenous system of medicine and which includes many remedial uses, such as anti-allergy, antianxiety, anti-convulsant, anti-diarrheal, anti-diabetic, anti-inflammatory, antimicrobial, anti-nociceptive, antioxidant, anti-spasmodic, anti-septic

${ }^{1}$ The Monitoring and Surveillance Center for Zoonotic Disease in Wildlife and Exotic Animals, Faculty of Veterinary Science, Mahidol University, Phutthamonthon, Nakhon Pathom, Thailand. ${ }^{2}$ Nakhonsawan Campus, Mahidol University, Nakhonsawan, Thailand. ${ }^{3}$ Department of Pre-Clinical and Applied Animal Science, Faculty of Veterinary Science, Mahidol University, Phutthamonthon, Nakhon Pathom, Thailand.*For Correspondence: kanjana.ass@mahidol.edu 
and antitussive treatment (Sanda et al., 2001; Peng et al., 2008). Phytochemistry has been studied in many parts of plants, which ensured in the isolation and identification of different terpenoids, flavonoid and tannins (Tanaka et al., 1992; Lozoya et al., 1994; Meckes et al., 1996). Meanwhile, guava (Psidium guajava L.) leaves contain phenolic, flavonoid, tannins and triterpene (Gutierrez et al., 2008). Guava leaves extract has been previously reported for its ingredient triterpenoids compound, which has been characterized as betulinic acid (Ghosh et al., 2010).

Betulinic acid (BA) is pentacyclic triterpene, which can be extracted from many plant species, such as numerous amounts of BA in the outer bark of a diversity of plant species, e.g. Betula alba and Betula pendula (Alakurtti et al., 2006; Gomathi et al., 2014). It is a natural product, which displays several biological effects, for example, antibacterial, anti-inflammatory, antiparasitic, antiviral and anticancer activity (Einzhammer and $\mathrm{Xu}$ 2004; Simone 2008; Wojciech et al., 2006). Moreover, BA has been demonstrated to suppress cancer growth (Fulda 2009). It has been exhibited anticancer curative effect in human cancers, such as brain tumors, cervical cancer, head and neck squamous carcinoma, leukemia, neuroectodermal tumors (Gomath et al., 2014), breast carcinoma (Tiwari et al., 2014), colorectal carcinoma (Jung et al., 2007), glioblastoma (Jeremias et al., 2004), lung carcinoma (Hsu et al., 2012), melanoma (Jeremias et al., 2004) and prostrate carcinoma (Rabi et al., 2008). However, the effect of BA on human cholangiocarcinoma cells has not formerly been determined. Used as remedies, BA from guava leaves can be used as natural remedies for diabetes, cardiovascular disease, obesity and atherosclerosis (Yadau et al., 2010). However, BA extracted from guava leaves has not been studied for its roles against cancer inhibition. In this study, we investigated the effect of BA extracted from guava leaves on human cholangiocarcinoma (HuCCA) cell viability and apoptosis in vitro. To our knowledge, this is the first report of its mechanism associated with the inhibition of HuCCA cell growth of BA extracted from guava leaves.

\section{Materials and Methods}

\section{Chemicals and reagents}

Dulbeco's modified Eagle's medium (DMEM) and fetal bovine serum (FBS) were purchased from Gibco (Carlsbad, USA). Dimethyl sulfoxide (DMSO), 3-(4, 5-dimethylthiazol-2-yl)-2, 5-diphenyltetrazolium bromide (MTT), Hoechst 33342, 5-fluorouracil (5-FU) were purchased from Sigma Inc. (St, Louis, Mo, USA). GENEzol reagent was purchased from (Geneaid biotech, Geneaid, Taiwan). RNeasy Mini Kit was purchased from Qiagen (Hilden, German). iScriptTM cDNA synthesis kit and iTaq green supermix system was purchased from Bio-Rad (Richmand, CA, USA). The other common reagents were obtained from the Department of Chemistry, Faculty of Science, Mahidol University and the Monitoring and Surveillance Center for Zoonotic Diseases in Wildlife and Exotic Animals, Faculty of Veterinary Science, Mahidol University Thailand.

\section{Cell culture}

Human cholangiocarcinoma (HuCCA) cell lines CL6 courtesy were provided by Associated Professor Dr. Adisak Wongkajornslip, the Department of Pharmacology, Faculty of Medicine Siriraj Hospital, Mahidol University. Baby hamster normal kidney (BHK-21) fibroblast cell line was obtained from the Monitoring and Surveillance Center for Zoonotic Diseases in Wildlife and Exotic Animals, Faculty of Veterinary Science, Mahidol University. The cells were cultured in Dulbecco's Modified Eagle Medium (DMEM), containing $10 \%$ fetal bovine serum (FBS) in which antibiotics were added (penicillin $100 \mathrm{IU} / \mathrm{mL}$, streptomycin $100 \mu \mathrm{g} / \mathrm{mL}$ ). All cell lines were routinely maintained at $37^{\circ} \mathrm{C}$ in an incubator with $95 \%$ humidity and $5 \% \mathrm{CO}_{2}$.

\section{Extraction and isolation of betulinic acid}

One kilogram of guava leaves were percolated with $2.0 \mathrm{~L}$ of $70 \%$ ethanol for $72 \mathrm{~h}$ twice at room temperature; the ethanol fraction was combined and evaporated in a vacuum chamber to give crude ethanol extract, which weighed $151.21 \mathrm{~g}$. The extract was dissolved in water and extracted with n-butanol. The organic fraction was evaporated in a vacuum chamber to give the crude extract of guava leaves. The crude extract of guava leaves $(10.1 \mathrm{~g})$ was separated by $\mathrm{Si}-\mathrm{Gel} \mathrm{CC}\left(\mathrm{SiO}_{2} 300 \mathrm{~g}\right.$, ethyl acetate-hexanes, $\mathrm{MeOH}$-ethyl acetate and $\mathrm{MeOH}$ gradients) to give fraction A1-A5. Fraction A4 (2.1 g) provided BA (341.00 mg) after two consecutive Si-gel CC $\left(\mathrm{CH}_{2} \mathrm{Cl}_{2}\right.$-hexanes gradients), followed by recrystallization with $\mathrm{CH}_{2} \mathrm{Cl}_{2}-\mathrm{MeOH}$.

BA was isolated as white crystals with dichloromethane in methanol, m.p. $278-279^{\circ} \mathrm{C}$. Its EIMS showed [M]+ peak at $\mathrm{m} / \mathrm{z} 456$ which established the molecular formula of $\mathrm{C}_{30} \mathrm{H}_{48} \mathrm{O}_{3}$. The FTIR spectrum has exhibited hydroxyl at vmax $3451 \mathrm{~cm}^{-1}$ and exomethylene at vmax 3060, 880 and $\mathrm{C}=\mathrm{O}$ stretching of carboxylic acid at $1,639 \mathrm{~cm}^{-1}$. The 1H NMR (500 MHz) spectrum (Figure 1A) showed the presence of methine proton on the carbon connected to oxygen in the structure which was indicated by the multiplet at $\delta 3.50(1 \mathrm{H}, \mathrm{t}, \mathrm{H}-3)$, two olefinic protons at $\delta 4.84(1 \mathrm{H} \mathrm{(s))}$ and $\delta 4.95(1 \mathrm{H}(\mathrm{s}))$. The signal revealed signals for five tertiary methyl at $0.80(\mathrm{H}-25), 1.10(\mathrm{H}-24)$, $1.14(\mathrm{H}-26), 1.20(\mathrm{H}-27)$ and $1.20(\mathrm{H}-23)$. This compound was proved to possess an isopropenyl group by the signal of a vinylic methyl at $\delta 1.78$ (s), and the olefinic methylene protons at $\delta 4.80$ (brs, H-29a) and 4.95 (brs, H-29b). These data indicated a pentacyclic triterpenoid of betulinic acid, confirmed by comparison with previously published data. The $125 \mathrm{MHz}$ 13C-NMR spectrum (Figure 1B) of this compound exhibited thirty signals for thirty carbons. The DEPT spectra (Figure 1C) indicated the present of the presence of six methyl carbons, ten methylene carbons, six methine carbons, six quaternary carbons and one carbonyl carbon. BA has been verified by the comparison of their physical properties and spectroscopic data with the data previously reported in the literature (Baek et al., 2010; Ghosh et al., 2010).

BA: white crystalline from methanol-dichloromethane, m.p. $278-279^{\circ} \mathrm{C}$ (Lit 282 oC); FT-IR (KBr) vmax $=3,451$ (O-H stretching), 2942, 1639 ( $\mathrm{C}=\mathrm{O}$ stretching), 1,453, 
$1,376,1,299,1,047,1,022,959,881 ;$ EIMS m/z (\% relative intensity): $456(\mathrm{M}+, 4), 411(25), 381(8), 248$ (39), 219 (15), $203(55), 189(100)$. Optical rotation: $+8^{\circ}$ (c 0.1 , pyridine).

\section{Cytotoxicity analysis}

The HuCCA cells and BHK-21 cells were seeded at into 96 wells tissue culture plate and incubated under 5\% $\mathrm{CO} 2$ at $37^{\circ} \mathrm{C}$ for $24 \mathrm{~h}$. Afterward, the cell were incubated for $24 \mathrm{~h}$ with BA and 5-FU at various concentrations (50, $100,200,400,800 \mu \mathrm{g} / \mathrm{mL})$ control $(0 \mathrm{ug} / \mathrm{mL})$ for each compound. Next, the medium was removed from each well. $100 \mu \mathrm{L}$ of MTT solution $(0.5 \mathrm{mg} / \mathrm{mL})$ was added into each well and the solution was incubated for $4 \mathrm{~h}$ at $37^{\circ} \mathrm{C}$ under the darkness (Christy et al., 2007). Then $100 \mu \mathrm{L}$ of DMSO was added into each well to solubilize the blue formazan products and incubated for $5 \mathrm{~min}$ in the dark at room temperature. The absorbance of the sample was determined spectrophotometrically at OD $490 \mathrm{~nm}$ using a microplate reader (Bio-Rad, Hercules, CA). The results were used to evaluated $50 \%$ inhibition concentration $\left(\mathrm{IC}_{50}\right)$. The cytotoxicity was determined by the MTT assay. The testing was done for three independent experiments.

\section{Nuclear Morphology assay}

The nuclear morphological changes correlative with apoptosis was analyzed by nuclear staining Hoechst 33342 (Sigma-Aldrich Co., St. Louis, MO, USA). After treatment with BA, HuCCA cells were fixed in cold methanol and acetic acid $(3 / 1, \mathrm{v} / \mathrm{v})$ at $4^{\circ} \mathrm{C}$ overnight. Later on, the cells were stained with Hoechst 33342 for $30 \mathrm{~min}$ in dark. Next, they were washed with PBS, mounted with $80 \%$ glycerol in PBS and assessed under a fluorescent microscope.

Quantitative real-time polymerase chain reaction for gene expression

Total RNA from HuCCA cells were extracted using GENEzol reagent (Geneaid biotech, Taiwan) and isolated using RNeasy Mini kit (Qiagen, German): one microgram of total RNA was treated with DNase I (Invitrogen, USA). The total RNA was converted to cDNA using iScriptTM cDNA synthesis Kit (Bio-rad, USA) according to manufacturer's protocol. Quantitative real-time PCR using define the exposition levels of Bcl-2, Bax, caspase- 3 and GAPDH were performed in Luna ${ }^{\circledR}$ Universal qPCR Master Mix (New England BioLabs, USA), and was processed in an ABI 7500 Real-time PCR system (Applied Biosystems, Foster City, CA). The specific primers were designed according to the full cDNA sequence of p53 (accession KY907142), Bax (accession
NM 003217), Bcl-2 (accession NM 021960), caspase-3 (accession NM_001354782), and GAPDH (accession NM_001256799) using Primer Blast Program (Ye et al., 2012). The following specific primers (Pacific Science Co., Ltd.) were used in table 1 . The conditions were as follows: the amplification primary incubation at $95^{\circ} \mathrm{C}$ for $10 \mathrm{~min}, 40$ cycles of denaturation at $95^{\circ} \mathrm{C}$ for $10 \mathrm{~min}$, annealing at $60^{\circ} \mathrm{C}$ for $1 \mathrm{~min}$, and extension at $60^{\circ} \mathrm{C}$ for 1 $\min$. The sequences of these PCR products were harvested by direct sequencing. Each amplicon was cloned into the PGEM $^{\circledR}$-t Vector (Promega, Madison, WI, USA) in order to establish standard curves for target cDNA. The mRNA level was informed as the ratios of the copy numbers of target cDNA to GAPDH cDNA. The ratio of fold alter in gene exposition level between the treatment and control cells is defined to identify the up down control of gene exposition.

\section{Statistical analysis}

Data of cell viability and quantitative real-time PCR were presented as mean $\pm \mathrm{SD}$ from three independent experiments. Statistical analysis was performed using by GraphPad Prism program version 8.0.1 (244) software. Analysis of variance (ANOVA) with Bonferroni post-test were used to compare the differences between the treated group and control group. P-values $<0.05$ was considered statistically significant.

\section{Results}

Cytotoxicity of BA on HuCCA and BHK-21

After the treatment with BA for $24 \mathrm{~h}$, the cell viability of HuCCA cells were decreased in the dose dependent manner from 50 to $800 \mu \mathrm{g} / \mathrm{mL}$ when compared with control group (Figure 2A). The average concentration of $50 \%$ inhibitory concentration $\left(\mathrm{IC}_{50}\right)$ on HuCCA cells were $92.45 \mu \mathrm{g} / \mathrm{mL}$. On the other hand, BHK-21 cells treated with BA at the concentration $50-800 \mu \mathrm{g} / \mathrm{mL}$ were higher than $50 \%$ cell viability (Figure $2 \mathrm{~A}$ ). This result exhibited low toxicity to normal cells. Moreover, the viability of HuCCA cells treated with BA was compared to 5-FU. The result indicated that the treatment with the BA and 5-FU has the similar effects on the decrement of HuCCA cell viability (Figure 2B).

\section{BA induce apoptosis in HuCCA cells}

In order to evaluate the nuclear morphological changes of treated cells, the analysis was performed by Hoechst 33342 staining. The comparison between the BA treated HuCCA cell group and the control group was performed. The result showed the treated cells are characterized as

Table 1. Primer Sequence Used for Quantitative Real-Time Polymerase Chain Reaction

\begin{tabular}{lll}
\hline Gene name & Forward primer & Reverse primer \\
\hline$p 53$ & GAACAGCTTTGAGGTGCGTG & AGAGGAGCTGGTGTTGTTGG \\
Bax & TCCCACCAGGCTTCATTCAC & CAGAGGGAGCAAAGCATCCA \\
Bcl 2 & TGCAGGTGTTGCTGGAGTAG & GCTAGGTTGCTAGGGTGCAA \\
caspase3 & GCTCATACCTGTGGCTGTGT & ACACCCACCGAAAACCAGAG \\
GAPDH & GTCAAGGCTGAGAACGGGAA & AAATGAGCCCCAGCCTTCTC \\
\hline
\end{tabular}


A

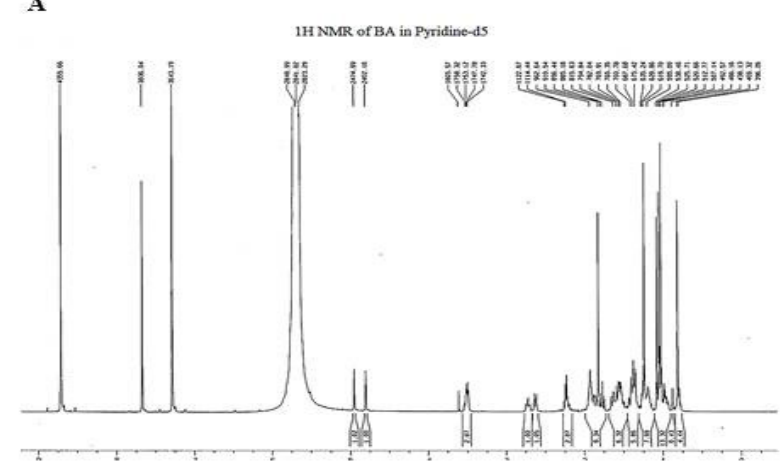

B

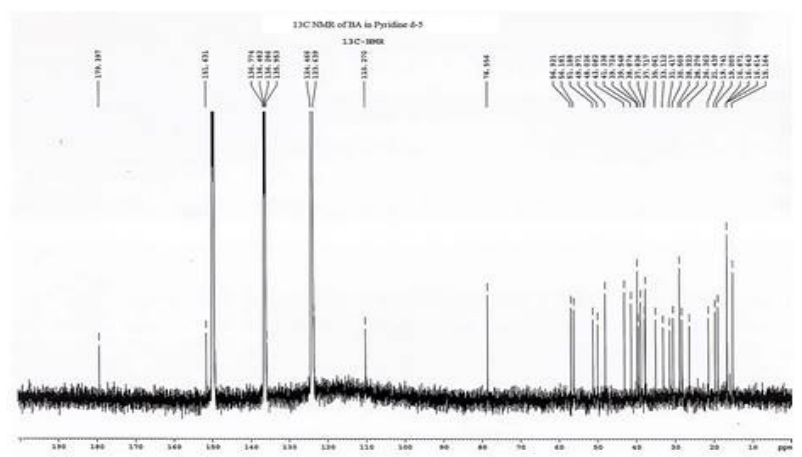

C

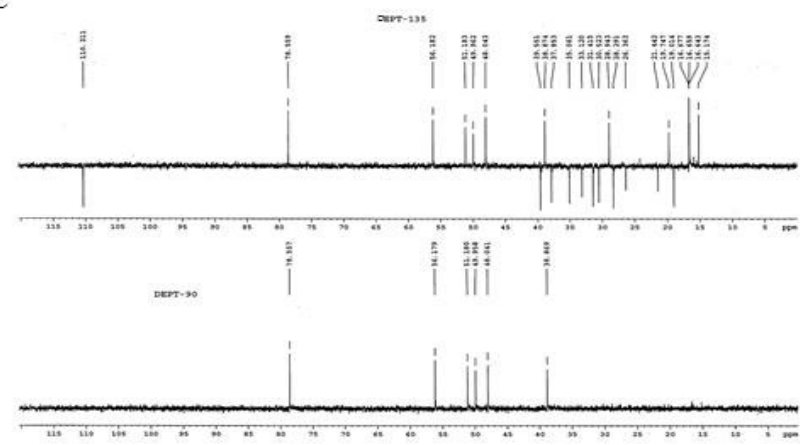

Figure 1. NMR Spectrum of Betulinic Acid Extracted from Guava (Psidium guajava Linn.) Leaves. (A) The H1 NMR (500 MHz), (B) The 13C NMR spectrum (125 MHz) and (C) The DEPT-135 and DEPT-90.

nuclear chromatin condensation and fragmentation which indicates nuclear damage in the treated cells (Figure 3B) whereas the control group shows uniform staining nuclei
(Figure 3A). Using the nuclear morphological changes indicative of apoptosis. This result suggests that BA could induce apoptosis in HuCCA cells.

A

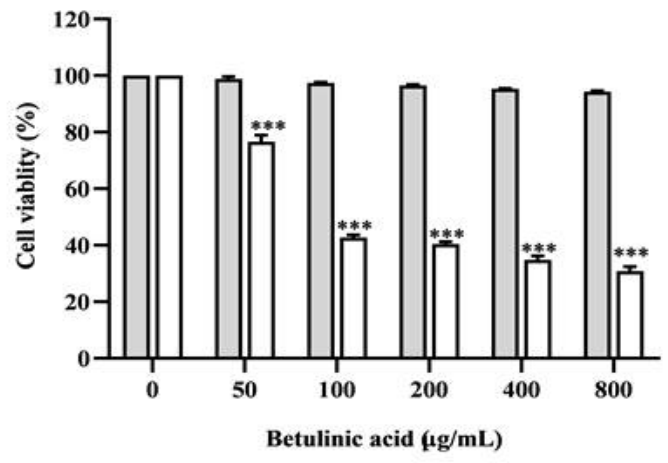

$\square$ BHK-21

$\square$ HuCCA

B

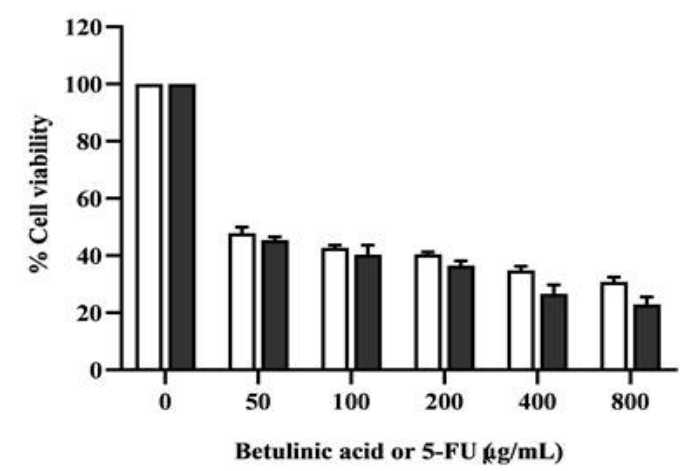

口 BA treated HuCCA

5-FU treated HuCCA

Figure 2. The Effect of BA on the Cell Viability by MTT Assay Examined at 24 h. (A) Cell viability of HuCCA and BHK-21 cell lines after treatment with BA. (B) Cell viability of HuCCA cells after treatment with BA compared with 5 -FU. All values are presented in mean $\pm \mathrm{SD}, * * * \mathrm{p}<0.001$. 
A

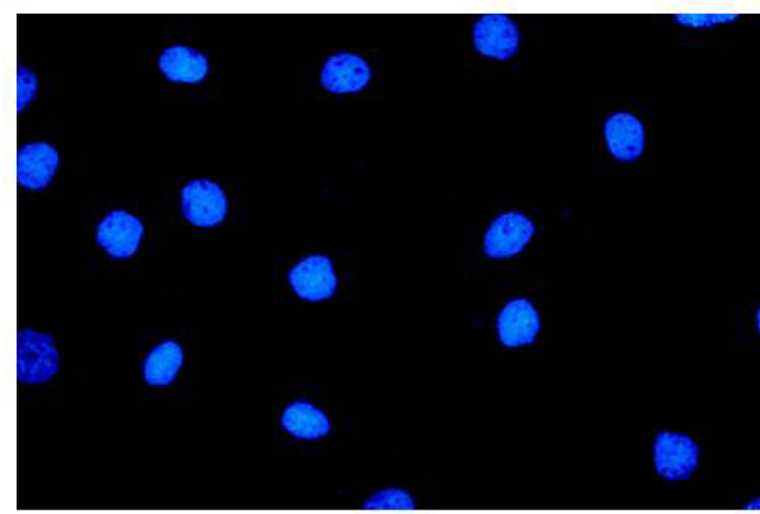

B

Betulinic acid

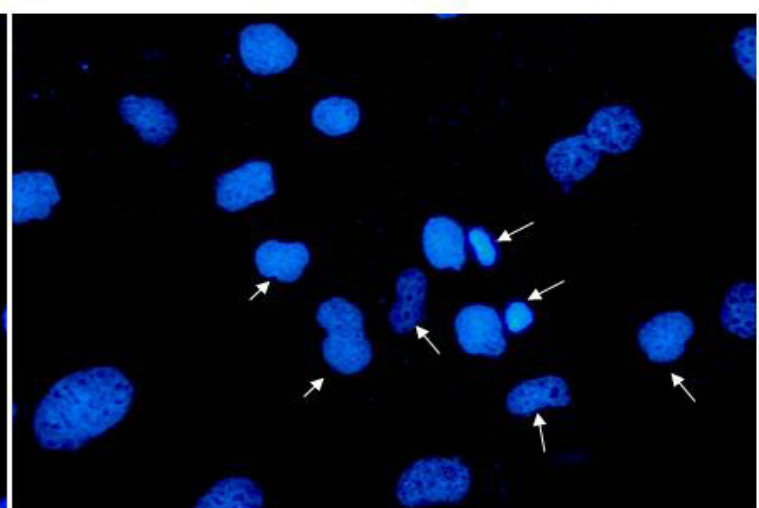

Figure 3. Apoptosis Involved Nuclear Condensation and Fragmentation on HuCCA Cells. After $24 \mathrm{~h}$ treatment with BA was stained with Hoechst 33342 and measured by fluorescence microscopy at 40x magnification. (A) Control and (B) BA treatment group. White arrows show condensed and fragmented nuclei as the characteristic of apoptosis.

\section{Effect of BA on gene expression}

The expression levels of Bax, Bcl-2, caspase-3 and $p 53$ in BA treated HuCCA cells were measured by Quantitative real-time PCR. The results showed that the treatment with BA increase p53, Bax and caspase-3 levels (Figure 4A, 4B and $4 \mathrm{C}$ ) but decreased $\mathrm{Bcl}-2$ levels in HuCCA cells in a dose-dependent manner when compared with the control group (Figure 4D). These resulted in an increasing ratio of $\mathrm{Bax} / \mathrm{Bcl}-2$ in the BA treated group in a dose-dependent manner (Figure 5). In all values obtained, statistically significant differences were found when compared to the control group $(\mathrm{p}<0.05)$.

\section{Discussion}

BA is a natural product that is isolated from many plant species. Guava (Psidium guajava Linn.) leaves are one of the plants contains that BA. This substance exerts several biological effects, such as antibacterial, anti-inflammatory, antiparasitic, antiviral and anticancer
$P 53$

A

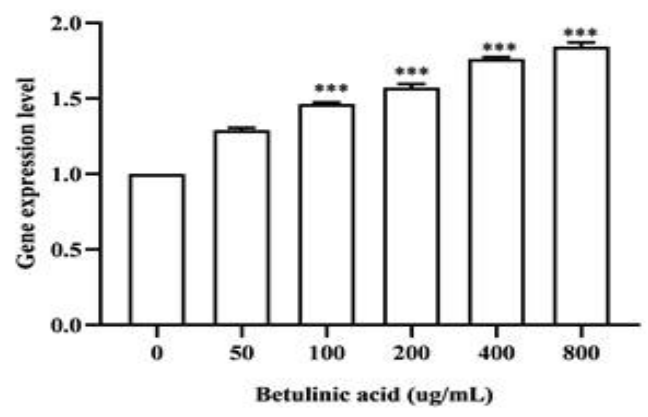

C

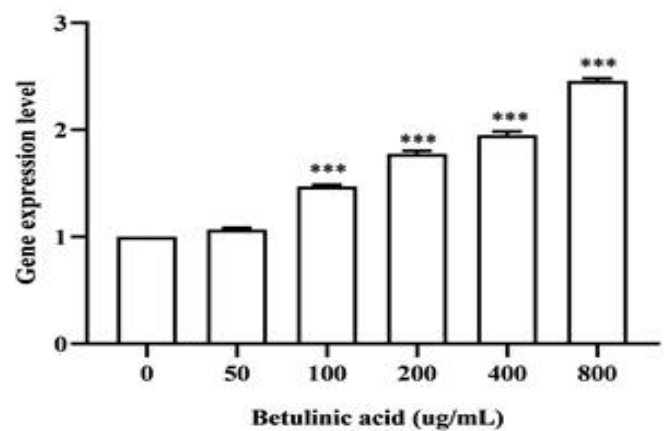

Bax

B

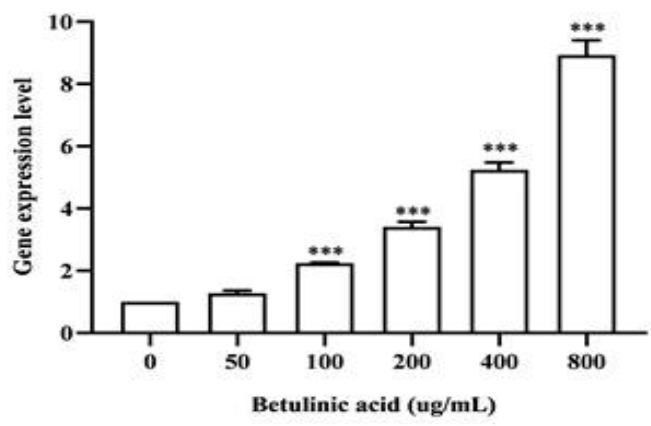

Bcl-2

D

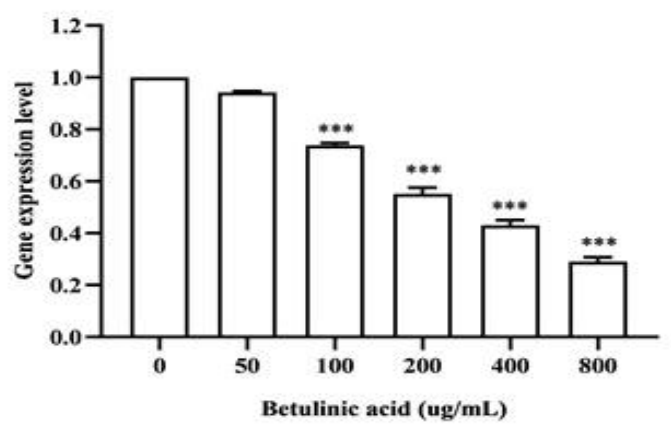

Figure 4. Gene Expression in HuCCA Cells after BA Treatment for $24 \mathrm{~h}$. Gene expression levels of (A) p53, (B) Bax, (C) Caspase-3, and (D) Bcl-2 were examined and compared with untreated group. *** p $<0.001$. 


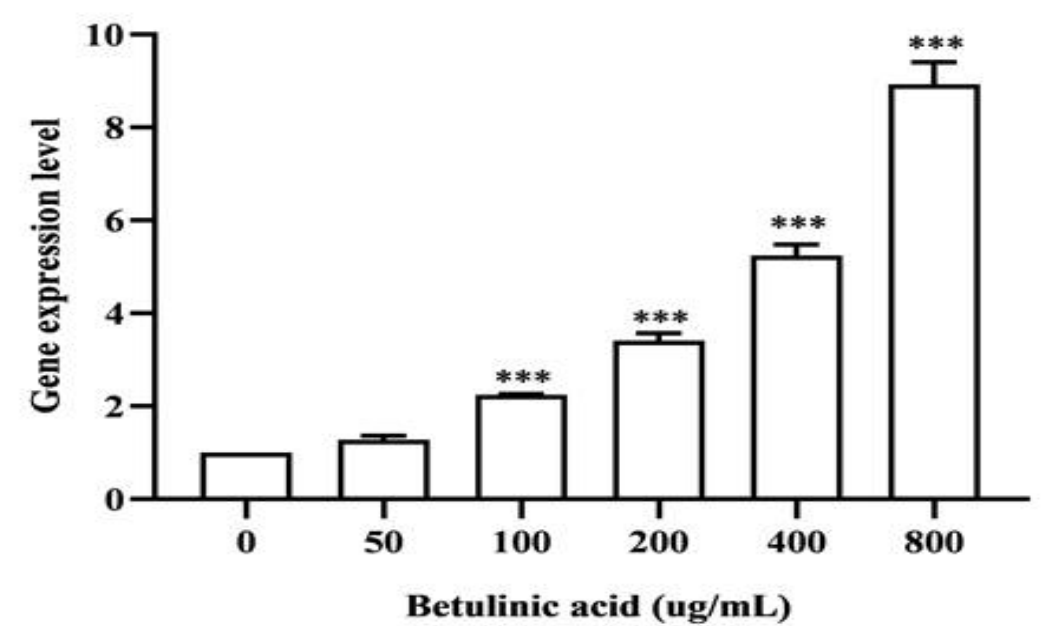

Figure 5. Gene Expression in HuCCA Cells after BA Treatment for 24 h. The ratio of Bax and Bcl-2, was examined and compared with untreated group. $* * * \mathrm{p}<0.001$.

activity (Einzhammer and Xu 2004; Simone 2008: Wojeiech et al., 2006). Meanwhile, there has been no previous reports about the cancer inhibition effect of BA isolated from guava leaves. This is the first report for the effect of guava leaves extract on the inhibition of human cholangiocarcinoma cells.

The current study displays the decrease in HuCCA cell viability in response to the BA which was extracted from guava (Psidium guajava Linn.) leaves. However, low toxicity of BA in BHK-21 cells was presented. Accordingly, the cancer cell viability was arrested by BA. Whilst there was less toxic effect than normal cells. Furthermore, the results also demonstrated both BA and 5-FU presents the similar actions on the reduction in HuCCA cell viability at the similar concentration, 5-FU is one of the chemotherapy used for cancer treatment. The previous research showed that 5-FU induces cancer cell necrosis, by which the normal cells are also affected (Chen et al., 2014). Our data demonstrated that apoptosis was induced following the treatment with the BA. The growth inhibition effect of BA on HuCCA cells was likely to be regulated through apoptosis because the cells exhibited the nuclear morphology which is typical characteristic of apoptosis including chromatin condensation and nuclear fragmentation. Evidently, the induction of apoptotic cell after treatment of BA leads to the reduction in HuCCA cell viability. In addition, the investigation of the expression levels of apoptosis involved genes in the BA treated cells showed an increase of Bax, caspase- 3 and $p 53$ genes whereas, the decrease of $\mathrm{Bcl}-2$ gene leading the up-regulation of $\mathrm{Bax} / \mathrm{Bcl}-2$ ratio was found. In our experiment BA enhanced $p 53$ gene expression. $p 53$ is a tumor suppressor gene. The $p 53$ can eradicate neoplastic cells which induced apoptosis (Kerr et al., 1972). The p53 activates the intrinsic pathway through the induction of Bax gene as pro-apoptotic gene in $B c l-2$ family (Thornborrow et al., 2002; Susan et al., 2003). The $B c l-2$ family are apoptosis controllers, which comprise anti-apoptotic gene $(B c l-2, M c l-1, B c l-x L)$ and pro-apoptotic genes (Bax, Bak, Bad) (Li et al., 2008). The $B c l-2$ family plays an essential role in the apoptosis pathway through the mitochondrial pathway (Green and Reed, 1998; Oltersdorf et al., 2005). The mitochondrial pathway is major induction of destruction in mitochondrial via differentiation of $\mathrm{Bax} / \mathrm{Bcl}-2$ ratio. Enhancing Bax activates the intrinsic apoptotic pathway by inducing permeabilization of the outer mitochondrial membrane, causes a release of cytochrome $\mathrm{C}$ into the cytoplasm and subsequently increase of caspase but, decrease in $B c l-2$ (Li et al., 2008; Tilli et al., 2002; Camin et al., 2008). Cytochrome $\mathrm{C}$ releasing from mitochondria directly stimulates caspase- 9 which result in caspase-3 stimulation. The caspase-3 plays a significant role in differentiating the nuclear DNA in apoptotic cells. (Tilli et al., 2002; Bras et al., 2005). BA extract from guava leaves could activate $p 53$ result in decrease HuCCA cell viability via intrinsic apoptosis pathway. This result was different from previous studies. BA, which is not extracted from guava leaves, will induce growth arrest of ovarian carcinoma (A 2780), cervix carcinoma (A 431) and small lung carcinoma (POGB) independent of $p 53$ gene (Zuco et al., 2002). Therefore, it was obvious that the induction of apoptotic cells after BA treatment was a cause of inhibiting in HuCCA cell viability. In this experiment, increase of p53, Bax, caspase-3 level and decrease of Bcl-2 level, result in increase $\mathrm{Bax} / \mathrm{Bcl}-2$ ratio in the BA treatment group promote HuCCA cells apoptosis.

In conclusion, our experiment demonstrates that the BA from guava leaves potentially inhibit the HuCCA cell viability and induce apoptosis in a dose-dependent manner. This apoptotic response was found to be correlated with the increase in $p 53$ and induce stimulation of pro-apoptotic gene (Bax). This gene plays a major role in apoptosis pathway through mitochondrial pathway leading to the increase in $\mathrm{Bax} / \mathrm{Bcl}-2$ ratio and also induce stimulation of caspase-3. Consequently, BA from guava leaves might be used as an energetic substance as a result of its capable viability inhibitors of HuCCA cells and low 
toxicity to normal cell. Mechanism of BA extract from guava leaves in vivo and modify BA structure also awaits further determination for development as agent used for the cholangiocarcinoma treatment.

\section{Author Contribution Statement}

Kanjana Assawasuparerk: Conceptualization,executi on,analysis of data and writing of article. Rassameepen Phonarknguen: execution and writing of parts of methodology section. Saksit Nobsathian execution, analysis of data and writing of parts of methodology section. All authors have read and agreed to the published version of the manuscript.

\section{Acknowledgements}

This research was financed by Faculty of Veterinary Science, Mahidol University. We would like to thank the Monitoring and Surveillance Center for Zoonotic Disease in Wildlife and Exotic Animals, Faculty of Veterinary Science, Mahidol University, for the laboratory support for this experiment.

\section{References}

Alakurtti S, Mäkelä T, Koskimies S, Yli-Kauthaluoma J (2006). Pharmacological properties of the ubiquitous natural product botulin. Eur J Pharm Sci, 29, 1-13.

Anand V, Manikandan, Kumar V, et al (2016). Phytopharmacological overview of Psidium gujava Linn. Phcog J, 8, 314-20.

Baek MY, Cho JG, Lee DY, et al (2010). Isolation of Triterpenoids from the Stem Bark of Albizia julibrissin and Their Inhibition Activity on ACAT-1 and ACAT-2. J Korean Soc Appl Biol Chem, 53, 310-15.

Battle TE, Arbiser J, Frank DA (2005). The natural product honokiol induces caspase-dependent apoptosis in B-cell chronic lymphocytic leukemia (B-CLL) cells. Blood, 106, 690-97.

Bras M, Queenan B, Susin SA (2005). Programmed cell death via mitochondria: different modes of dying. Biochemistry (Mosc), 70, 231-9.

Camin A, Pallas M, Silverstre JS (2008). Apoptotic mechanisms involved in neurodegenerative diseases: experimental and therapeutic approaches. Methods Find Exp Clin Pharmacol, 20, 43-65.

Chen K-C, Hsieh C-L, Peng CC, et al (2007). Brain derived metastatic prostate cancer DU-145 cell are effectively inhibited in vitro by guava (Psidium guajava L.) leaf extracts. Nutr Cancer, 58, 93-106.

Christy CB, Jamie RB, Rudolfs KZ (2007). Transport of thiolconjugates of inorganic mercury in human retinal pigment epithelial cells. Toxicol Appl Pharmacol, 221, 251-60.

Einzhammer DA, Xu Z-Q (2004). Betulinic acid: a promising anticancer candidate. IDrugs, 4, 359-78.

Fava G, Lorenzini I (2011). Molecular pathogenesis of cholangiocarcinoma. Int J Hepatol, 2012, 1-7.

Fulda S (2009). Betulinic acid: a natural product with anticancer activity. Mol Nutr Food Res, 6, 13671-87.

Gatto M, Bragazzi MC, Semeraro R, et al (2010). Cholangiocarcinoma: Update and future perspectives. Dig Liver Dis, 42, 253-60.

Gertsch J, Sticher O, Schmidt T, Heilmann J (2003). Influence of helenanolide-type sesquiterpene lactones on gene transcription profiles in Jurkat $\mathrm{T}$ cells and human peripheral blood cells: anti-inflammatory and cytotoxic effects. Biochem. Pharmacol, 66, 2141-53.

Ghosh P, Mandal A, Chakraborty P, et al (2010). Triterpenoids from Psidium guajava with biological activity. Indian $J$ Pharm Sci, 72, 504-7.

Gomathi P, Girma T, Mebrahtom G, et al (2014). Betulinic and its derivatives as anti-cancer agent: A review. Arch Appl Sci Res, 6, 47-58.

Gores GJ (2003). Cholangiocarcinoma: current concepts and insights. Hepatology, 37, 961-69.

Green DR, Reed JC (1998). Mitochondria and apoptosis. Science, 281, 1309-12.

Gutierrez RM, Mitchell S, Solis RV (2008). Psidium guajava: A review of its traditional uses, phytochemistry and pharmacology. J Ethnopharmacol, 117, 1-27.

Haswell-Elkins MR, Mairiang E, Mairiang P, et al (1994). Cross-sectional study of Opisthorchis viverrini infection and cholangiocarcinoma in communities within a high-risk area in northeast Thailand. Int J Cancer, 59, 505-9.

Hejna M, Pruckmayer M, Raderer M (1998). The role of chemotherapy and radiation in management of biliary cancer: a review of the literature. Eur J Cancer, 34, 977-86.

Hsu TI, Wang MC, Chen SY, et al (2012). Betulinic acid decreases specificity protein I (Sp1) level via increasing the sumoylation of sp1 to inhibit lung cancer growth. Mol Pharmacol, 82, 1115-28.

Jeremias I, Steiner HH, Benner A, Debatin KM, Herold-Mende C (2004). Cell death induction by betulinic acid, ceramide and TRAIL in primary glioblastoma multiforme cells. Acta Neurochir (Wien), 146, 721-29.

Jung GR, Kim KJ, Choi CH, et al (2007). Effect of betulinic acid on anticancer drug-resistant colon cancer cells. Basic Clin Pharmacol Toxicol, 101, 277-85.

Kerr JF, Wyllie AH, Curre AR (1972). Apoptosis: a basic biological phenomenon with wide-ranging implications in tissue kinetics. Br J Cancer, 26, 239-57.

Koehn FE, Carter GT (2005). The evolving role of natural products in drug discovery. Nat Rev Drug Discov, 4, 206-20.

Li X, Roginsky AB, Ding XZ, et al (2008). Review of the apoptosis pathways in pancreatic cancer and the anti-apoptotic effect of the novel sea cucumber compound, Frondoside A. Ann N Y Acad Sci U S A, 1138, 181-93.

Lozoya X, Meckes M, Abou-Zaid M, et al (1994). Quercetin glycosides in Psidium guajava L. leaves and determination of a spasmolytic principle. Arch Med Res, 25, 11-5.

Mann J (2002). Natural products in cancer chemotherapy: past, present and future. Nat Rev Cancer, 2, 143-8.

Meckes M, Calzada F, Tortoriello J, Gonzalez JL, Martinez M (1996). Terpenoids isolated from Psidium guajava hexane extract with depressant activity on central nervous system. Phytother Res, 10, 600-3.

Olterdrof T, Elmore SW, Shoemaker AR, et al (2005). An inhibitor of Bcl-2 family proteins induces regression of solid tumors. Nature, 435, 677-81.

Peng RY, Hsieh CL, Chen KC (2008). Review on the medicinal uses of Psidium guajava L. Pharmacol Ther, 20, 215-48.

Rabi T, Shukla S, Gupta S (2008). Betulinic acid suppresses constitutive and TNF alpha-induced NF-kappa B activation and induces apoptosis in human prostate carcinoma PC-3 cells. Mol Carcinog, 47, 964-73.

Rita CS, Jorge ARS, Silvia M, Marta C (2009). Novel semisynthetic derivatives of botulin and betulinic acid with cytotoxicity activity. Bioorg Med Chem, 17, 6241-50.

Sanda KA, Grema HA, Geidam YA, Bukar-Kolo YM (2011). Pharmacological aspects of Psidium guajava: An update. 
Int J Pharmacol, 7, 316-24.

Shin HR, Oh JK, Masuyer E, et al (2010). Epidemiology of cholangiocarcinoma: an update focusing on risk factors. Cancer Sci, 101, 579-85.

Simone F (2008). Betulinic acid for cancer treatment and prevention. Int J Mol Sci, 9, 1096-107.

Sirica AE (2005). Cholangiocarcinoma: molecular targeting strategies for chemoprevention and therapy. Hepatology, 41, 5-15.

Sripa B, Bethony JM, Sithithaworn P, et al (2011). Opisthorchiasis and Opisthorchis-associated cholangiocarcinoma in Thailand and Laos. Acta Trop, 120, 148-68.

Sripa B, Pairojkul C (2008). Cholangiocarcinoma: lessons from Thailand. Curr Opin Gastroenterol, 24, 349-56.

Susan H, Michael B, Zehavit G, Ygal H (2003). Apoptosis-The p53 network. J Cell Sci, 116, 4077-85.

Tanaka T, Ishida N, Ishimatsu M, Nonaka G, Nishioka I (1992). Tannins and related compounds. CXVI. Six new complex tannins, guajavins, psidinins and psiguavin from the bark of Psidium guajava L. Chem Pharm Bull, 40, 2092-98.

Tilli CM, Stavast-koey AJ, Ramaekers FC, Neumann HA (2002). Bax expression and growth behavior of basal cell carcinomas. J Cutan Pathol, 29, 79-87.

Thornborrow EC, Patel S, Mastropietro AE, Schwartzforb EM, Manfred JJ (2002). A conserved intronic response element mediates direct $\mathrm{p} 53$-dependent transcriptional activation of both the human and murine bax genes. Oncogene, 21, 990-99.

Tiwari R, Puthli A, Balakrishnan S, Sapra BK, Mishra KP (2014). Betulinic acid-induced cytotoxicity in human breast tumor cell lines MCF-7 and T47D and its modification by tocopherol. Cancer Investig, 32, 402-8.

Wojciech R, Andrzej S, Marek S, et al (2006). Betulinic acid decreases expression of bcl-2 and cyclin D1, inhibits proliferation, migration and induces apoptosis in cancer cells. Naunyn Schmiedebergs Arch Pharmacol, 374, 11-20.

Yadav VR, Prasad S, Sung B., Kannappen R, Aggarwal BB (2010). Targeting inflammatory pathways by triterpenoids for prevention and treatment of cancer. Toxins, 2, 2428-66.

Ye J, Coulouris G, Zaretskaya I, et al (2012). Primer-BLAST: A tool to design target-specific primers for polymerase chain reaction. BMC Bioinform, 13, 134.

Zuco F, Supino R, Righetti SC, et al (2002). Selective cytotoxicity of betulinic acid on tumor cell lines, but not on normal cells. Cancer Lett, 175, 17-25.

\section{(ब) $(\mathbb{8}$}

This work is licensed under a Creative Commons AttributionNon Commercial 4.0 International License. 